\title{
A literature review on the state of pharmacy education in Zambia
}

\author{
Usman Abubakar Haruna ${ }^{1}\left(0\right.$, Oladunni Amos Abimbola1 ${ }^{\circledR}$, Musa Sulaiman Muhammad ${ }^{1}{ }^{(0)}$, Knovicks \\ Simfukwe 2, Don Eliseo Lucero-Prisno III ${ }^{3}$ \\ 1 Faculty of Pharmaceutical Sciences, Ahmadu Bello University, Zaria, Nigeria \\ 2 School of Veterinary Medicine, University of Zambia, Lusaka, Zambia \\ ${ }^{3}$ Department of Global Health and Development, London School of Hygiene and Tropical Medicine, London, United Kingdom
}

\author{
Keywords \\ Competencies \\ Curricula \\ State of the art \\ Pharmacy education \\ Zambia

\section{Correspondence} \\ Usman Abubakar Haruna \\ Department of Pharmacology and \\ Toxicology \\ Faculty of Pharmaceutical Sciences \\ Ahmadu Bello University \\ Zaria \\ Nigeria \\ khaliphate13@gmail.com
}

\begin{abstract}
Aim: The aim of this paper is to provide a narrative review of pharmacy education in Zambia, in terms of: overview of the historical development of pharmacy education, the current state of pharmacy education and successes achieved, efforts made to provide pharmacists with the requisite competency and recommendations for future directions. Method: A literature search was conducted in November 2020 on PubMed, Google scholar and Medscape databases, the search was confined to research articles published between 2002 to 2021 . Result: A total of 23 journal articles were retrieved, articles that capture reports on the state of pharmacy education in Zambia were reviewed. Conclusion: Pharmacy education has undergone a series of modifications over the past few decades in an effort to fulfil the changing demands of society. For a pharmacy education system to thrive, it must be continually evolving and driven by the needs of society or nation at hand at all times. This involves updating the pharmacist in training with up-to-date skills required of the modern-day pharmacist and research that enables continual improvement of the education system.
\end{abstract}

\section{Introduction}

Zambia sits on a high tableland in South-Central Africa bordered to the north and north-east by the Democratic Republic of Congo and the United Republic of Tanzania; to the east and south-east by Malawi and Mozambique; to the south by Zimbabwe and Botswana; to the west by Namibia and Angola. Zambia has a population of 17 million people (World Bank, 2019) and is endowed with numerous mineral resources. Globally, there has been an underscore demand to advance the pharmaceutical workforce towards achieving universal health coverage (UHC) and Global Sustainable Development Goals (GSDGs). Hence, an understanding of pharmacy education in Zambia is important concerning national and international needs for pharmaceutical care services.
According to Anderson and colleagues (2009), pharmacy education is referred to as the educational design and capacity to develop the workforce for a diversity of settings (e.g. community, hospital, research and development, and academia) across varying levels of service provision and competencies (e.g. technical support staff, pharmacists and pharmaceutical scientists) and scope of education (e.g. undergraduate, postgraduate, lifelong learning). The responsibilities of pharmacists have evolved from medicine compounders to medical experts within the network of multidisciplinary healthcare professionals (Pearson, 2007). In response to the extended role of pharmacists, many countries have restructured pharmaceutical education and training processes to meet evolving healthcare demands (FIP, 2014). This paper aims 
to provide a narrative review of pharmacy education in Zambia, in terms of: overview of the historical development of pharmacy education, the current state of pharmacy education and successes achieved, efforts made to provide pharmacists with the requisite competency and to provide recommendations for future directions.

\section{Methods}

A literature search on pharmacy education in Zambia was carried out in November 2020 by means of a multiple electronic database search. We conducted the search in PubMed, Google Scholar and Medscape using keywords like 'pharmacy', 'education', 'curricula', 'state of art', 'competency', 'Zambia'. The search was limited to academic literatures published between 2002 and 2021, referring to pharmacy education in Zambia including reports written by organisations. The review included fulltext articles, abstracts and reports. A total of 23 articles were reviewed. The search terms included combinations intended to capture report of the state of pharmacy education in Zambia under the theme Zambia and pharmacy education, history of pharmacy education, schools that offer pharmacy degree, percentage of courses that contribute to the award of the degree, overview of pharmacy curriculum, entry requirements, regulation, competency and future direction. Studies that do not include pharmacy education in Zambia were not included in the review. It is of note that references cited in the articles used were included if eligible.

\section{Results}

\section{History of pharmacy education in Zambia}

Pharmacists' training began at overseas training institutions of different countries before localising degree training in Zambia. Those who returned to Zambia to contribute professionally, were supported by locally trained pharmacy technologists dating as far back as early 1970. Although the need for professional competent requirements necessitated overseas sourcing and training of other health professionals including pharmaceutical personnel at the time, the approach proved to be unreliable and expensive concerning the expected outcome. The curriculum adopted by overseas training institutions did not address local competence requirements in terms of pharmaceutical workforce, education, access to quality medicines, and awareness of the responsibility of pharmacists to provide pharmaceutical care (UNZA, 2002; Whitmarsh, 2008).

In addition, there was a limited number of available trained personnel for national health services per given time. As a result of limited personnel, some individuals were sponsored to undergo an overseas pharmacy training; after which around three quarters of those sponsored failed to return home to fulfill their sponsorship responsibilities due to an inability to complete the prescribed training programme or they chose to remain and work abroad. This situation resulted in underperformance of the comprehensive national health service delivery system arising from limited pharmaceutical personnel and poor pharmaceutical care service delivery. Some pharmaceutical care lines became almost non-existent (Lungwani, 2015). Therefore, the need to develop and promote local training of pharmacists to address contemporary pharmaceutical care needs became a national priority in Zambia. Pharmaceutical human resource development strategies started as early as the mid-1980s but materialised in the early part of the year 2000 (University of Zambia, 2002).

In 1998, the Ministry of Health in Zambia developed the Zambia National Drug Policy, which provided policy guidelines on elements of health services including human resource development. The policy under the element of human resource development seeks to address the pharmaceutical workforce needs via training of an adequate number of pharmaceutical personnel to meet the country's pharmaceutical care demands. To this end, the University of Zambia, housed by the University Teaching Hospital offered a commitment to initiate localised training and certification of pharmacists in Zambia (Lungwani, 2015).

The training was initiated by a team of experts who developed a curriculum that was to be approved via the established University of Zambia senate. At the time of initiation, under the University regulation, it was found to be most appropriate to establish a pharmacy training programme under the existing training unit of the university and the School of Medicine (specifically under Physiological Sciences) in the interim after which improvement can be undertaken to transform the department into a school. The programme was designed to run for five years starting from the School of Natural Sciences and to get students from the Evelyn Home College enrolled into the third year of the degree programme via the diploma certificate pathways. In addition, the pharmacy training programme was intended to improve general management of HIV/AIDS by generating appropriately trained personnel that are 
Table I: Pharmaceutical training institutions in Zambia

\begin{tabular}{|c|c|c|c|c|c|c|}
\hline Institutions & Year established & Sector & Location & Programmes offered & Mode of study & Duration \\
\hline Evelyn Home University & 1963 & Public & Lusaka & Diploma in Pharmacy Technology & Full-time & Three years \\
\hline University of Zambia & 1965 & Public & Lusaka & B.Pharm.* & Full-time & Five years \\
\hline Mulungushi University & 2008 & Public & Kabwe & B.Pharm.* & Full-time & Five years \\
\hline Lusaka Apex Medical University & 2008 & Private & Lusaka & B.Pharm.* & Full-time & Five years \\
\hline Gideon Robert University & 2010 & Private & Lusaka & $\begin{array}{l}\text { B.Pharm.* } \\
\text { B.Pharm. Sc.** }\end{array}$ & Full-time & Five years \\
\hline Livingstone International University & 2012 & Private & Lusaka & BSc.Pharm.*** & Full-time & Five years \\
\hline Texila American University & 2015 & Private & Lusaka & $\begin{array}{l}\text { DIP.Pharm. }{ }^{+} \\
\text {B.Pharm. }^{*}\end{array}$ & $\begin{array}{l}\text { Full-time } \\
\text { Full-time }\end{array}$ & $\begin{array}{l}\text { Three years } \\
\text { Four years }\end{array}$ \\
\hline Levy Mwanawasa Medical University & 2019 & Public & Lusaka & Pharm. $D^{++}$ & Full-Time & Six years \\
\hline $\begin{array}{l}\text { *Bachelor of Pharmacy } \\
\text { ** Bachelor of Pharmaceutical Science } \\
\text { *** Bachelor of Science in Pharmacy } \\
\text { +Diploma in Pharmacy } \\
+ \text { +Doctor of Pharmacy }\end{array}$ & & & & & & \\
\hline
\end{tabular}

competent in national HIV prevention initiatives such as the provision of ARV, rational drug use, medication and treatment counseling, and proper storage of ARV drugs. To impart clinical knowledge of pharmacy (pharmaceutical care) in pharmacy students while maintaining the scientific basis of pharmacy, students were exposed to the clinical application of this knowledge (Lungwani, 2015).

A total of 27 direct entry students with a diploma in pharmacy were enrolled in the third year and 26 from the School of Natural Sciences were enrolled the School of Pharmacy in the first academic year of the programme. The number increased to 40 students from the School of Natural Sciences the following year due to increased demand to undertake the course. In 2010, due to limited capacity to meet the increasing demand for the programme, a departmental-based programme was initiated that created a parallel training programme for direct entry students, increasing the direct entry slot from ten to 50 per year. Since the first graduating set of students in 2004, there has been a steady rise in the number of graduating students with the Bachelor of Pharmacy Degree (B.Pharm.) and most of the graduates have been employed by the Ministry of Health (Lungwani, 2015).

\section{Schools that offer Pharmacy programmes}

The University of Zambia (UNZA), which is the oldest and largest public university in Zambia, was the first institution to host local training of pharmacists at the degree level (UNZA, 2002). The university together with a network of collaborating organisations including the Ministry of Health and the Pharmaceutical Society of Zambia (PSZ) implemented a five-year undergraduate bachelor of pharmacy degree programme with a curriculum designed to address pharmaceutical needs within the local context. While other countries such as the United States of America (USA) and some countries in Asia, including low and middle-income countries (LMICS), have begun adopting curriculi leading to the award of Doctor of Pharmacy Degree (Anderson \& Futter, 2009) and Master of Pharmacy (M.Pharm.) degree at universities in the United Kingdom (UK) and Europe (Sosabowski \& Gard, 2008), Zambia's rational for adopting the B.Pharm. degree was due to local context demand and nationally acceptable higher level qualification gradient. Also, the adoption of the M.Pharm. or Pharm.D. programme was not an acceptable description for professional undergraduate degree programmes since they are commonly reserved for postgraduate level qualification.

Currently, there are eight higher learning institutions training pharmacists in Zambia including one institution training pharmaceutical technologists. These include four public institutions and four private institutions (Table I). As of 2016, over 700 pharmacists have been trained locally to address contemporary pharmaceutical care needs (HPCZ, 2016).

\section{Percentage of courses that contribute to the award of the degree}

The B.Pharm. curriculum in Zambia is structured to provide pharmacists with the requisite knowledge and skills to deliver pharmaceutical care services within a local context (UNZA, 2013). Core subject areas required for the completion of the degree include pharmacology, pharmaceutics, biopharmaceutics, pharmacology, pharmaceutical chemistry, clinical pharmacy, and pharmacy practice (UNZA B. Pharm. Curriculum, 2013). The training adopted for pharmacists in Zambia is similar 
to the subject focus areas offered in the UK and USA. It is comprised of a $60 \%$ theoretical-based approach and a $40 \%$ practical and problem-solving approach in clinical areas (UNZA, 2013).

\section{Overview of Bachelor of Pharmacy curriculum}

Pharmacy students undertake a foundational course in basic health science in the school of natural sciences before entry into the school of pharmaceutical education first year. In the second year, the students are exposed to the foundational knowledge on anatomy, biochemistry, physiology, social sciences, ICT and information management system. In the third and fourth-year, students undertake rigorous training on advanced pharmaceutics, radio- and bio-pharmaceutics, pharmacology and toxicology, pathology and pathophysiology, clinical pharmacy and pharmacy practice, pharmacognosy, and drug development, quality control of medicines, supply chain management, epidemiology, and biostatistics, among other courses, this is called the preclinical stage. In the fifth year, students are exposed to a minimum of six months of clinically oriented subject areas (UNZA, 2017). Table II summarises the details of each course by year.

Through a relationship with the ministry of health, pharmacy students are enrolled in practical and clinical learning modules at the University of Zambia Teaching Hospitals under the supervision of preceptors who are practicing pharmacists at the hospitals (UNZA, 2002). This is experiential learning that exposes students to hospital practicing training on prescription review and patient counseling in specialised clinical departments at the University of Zambia Teaching Hospitals. The absence of clinical learning laboratories, the growing number of pharmacy students in training institutions including limited hospital infrastructure, and the high student preceptor ratio have limited the capacity of public and private health facilities to train student pharmacists in Zambia (Kalungia et al., 2019). There is a need for further studies to evaluate the impact of limited hospital training infrastructure on the quality of clinical skills and pharmaceutical care of pharmacy students in Zambia.

\section{Entry requirement}

Admission into the school of pharmacy in Zambia is through the award of an ordinary O-level school certificate following successful completion of secondary school education. Entry into higher educational levels requires an O-level school certificate which is equivalent to the UK's
Table II: Overview of the revised Bachelor of Pharmacy curriculum (Adapted from: Kalungia and colleagues (2019))

\begin{tabular}{|c|c|c|}
\hline $\begin{array}{l}\text { Academic } \\
\text { year }\end{array}$ & Subject focus areas & Courses \\
\hline First-year & $\begin{array}{l}\text { Introduction to } \\
\text { General Basic } \\
\text { Sciences }\end{array}$ & $\begin{array}{l}\text { Mathematics, Biology, Chemistry, and } \\
\text { Physics. }\end{array}$ \\
\hline $\begin{array}{l}\text { Second- } \\
\text { year }\end{array}$ & $\begin{array}{l}\text { Introductory basic } \\
\text { Science } \\
\text { components of } \\
\text { pharmaceutical } \\
\text { education }\end{array}$ & $\begin{array}{l}\text { Pharmaceutical Chemistry, Basic } \\
\text { \& Metabolic Biochemistry, } \\
\text { Physical Pharmacy, Comparative } \\
\text { Physiology \& Anatomy, } \\
\text { Molecular Cell Biology, } \\
\text { Pharmaceutical Microbiology, } \\
\text { Behavioral \& Social Sciences, } \\
\text { ICT \& Information Management } \\
\text { Systems }\end{array}$ \\
\hline $\begin{array}{l}\text { Third- } \\
\text { year }\end{array}$ & $\begin{array}{l}\text { Fundamental } \\
\text { knowledge and } \\
\text { application of } \\
\text { pharmaceutical } \\
\text { sciences }\end{array}$ & $\begin{array}{l}\text { Pharmaceutics, Pharmacology, } \\
\text { Pharmacognosy, Pharmaceutical } \\
\text { Mathematics, Radiopharmacy, } \\
\text { Pathology \& Pathophysiology, } \\
\text { Basics of Pharmacy Practice, } \\
\text { Pharmaceutical Analysis \& } \\
\text { Quality Control of Medicines, } \\
\text { Pharmacovigilance }\end{array}$ \\
\hline $\begin{array}{l}\text { Fourth- } \\
\text { year }\end{array}$ & $\begin{array}{l}\text { Students gradually } \\
\text { transition to } \\
\text { operational and } \\
\text { procedural } \\
\text { application of } \\
\text { knowledge and } \\
\text { skill relevant to the } \\
\text { practice of } \\
\text { pharmacy }\end{array}$ & $\begin{array}{l}\text { Medicinal Chemistry, } \\
\text { Biopharmacy, Pharmacology \& } \\
\text { Toxicology, Business } \\
\text { Entrepreneurship, } \\
\text { Pharmacoeconomics, Professional } \\
\text { Pharmacy Practice, Clinical } \\
\text { Pharmacognosy \& Nutraceutics, } \\
\text { Research Methodology, } \\
\text { Epidemiology \& Biostatistics }\end{array}$ \\
\hline Five-year & $\begin{array}{l}\text { Student-centered } \\
\text { and experiential } \\
\text { learning which } \\
\text { includes: clinical } \\
\text { rotations, industrial } \\
\text { \& community } \\
\text { placements, } \\
\text { seminars and } \\
\text { research projects }\end{array}$ & $\begin{array}{l}\text { Clinical Pharmacy, Leadership, } \\
\text { Management \& Governance, } \\
\text { Pharmaceutical \& Biotechnology, } \\
\text { Pharmaceutical Engineering, } \\
\text { Community Pharmacy, Hospital } \\
\text { Pharmacy, Veterinary Pharmacy, } \\
\text { Industrial Pharmacy, } \\
\text { Pharmaceutical Supply Chain } \\
\text { Management, Research Project }\end{array}$ \\
\hline
\end{tabular}

General Certificate of Secondary Education (GCSE) and USA's High School Diploma. Prospective students are expected to meet at least one of the following criteria to be admitted into the B.Pharm degree programme (UNZA, 2013):

i.Candidates must have an O-level school certificate with a minimum of five credit passes or higher in relevant science subjects, including English language, and have completed advanced A-level equivalent subjects, including: Biology, Chemistry, Physics, and Mathematics at pre-pharmacy foundation year in the University.

ii.Candidates who have four A-level passes in the requisite science subjects (Biology, Chemistry, Physics, 
and Mathematics) who have other relevant academic qualifications in a health-related discipline in addition to the $\mathrm{O}$ - level school certificate required for admission to the University.

iii.Candidates with a diploma in pharmacy technology in addition to possessing an O-level certificate with passes in required subjects suitable for admission into the programme.

\section{Regulation}

Health professional educational programmes including pharmacy education are regulated by the Health Professional Council of Zambia (HPCZ) and the Higher Education Authority (HEA). The HPCZ regulates all health professions, except the nursing profession which is exclusively regulated by other legislation (Kalungia et al., 2019). The role of HPCZ includes registration of all health professionals including pharmacists and regulation of their professional conduct; licensing and regulation of all health facilities; accreditation of healthcare services provided by health facilities and registration and approbation of training programs for health professionals including pharmacists (HPCZ, 2016). The HEA is a statutory body that regulates higher education in Zambia (HEA, 2017). Academic institutions training health professionals must be accredited and approved by both HPCZ and HEA. The boards ensure that academic training institutions meet the benchmark of accreditation for training pharmacists in Zambia (Kalungia et al., 2019).

\section{Competency and future direction}

Pharmacy education has evolved in a bid to meet the rapidly changing demands of healthcare globally (Ifunanya, 2016). While the number of qualified pharmacists has increased significantly in the last ten years, the quality of pharmaceutical care service is an area which still requires improvement (Kalungia \& Kamanga, 2016). This is due to an inadequate policy framework that promotes the expanded responsibility of pharmacists in the provision of comprehensive patient care (Kalungia et al., 2019). There is a need to promote the development of policies which support an extended role of pharmacists within the framework of comprehensive patient care. Advances in pharmacy education in other countries, such as the USA, Canada, India, Pakistan, and South Africa, can be adopted to appraise the future of pharmacy education in Zambia. This is due to the evolving and changing pattern of diseases, emerging patient care needs, population changes, and evolving hospital-based care (Anderson \&
Futter, 2009). There is a need to enhance context-specific pharmaceutical care competency in Zambia while focusing on global trends (Kalungia et al., 2019). This can be achieved by strengthening the regulatory framework including the quality of pharmacy education through infrastructural development.

Pharmacy education in Zambia has the potential to be directed towards addressing contemporary pharmaceutical care needs. Studies have highlighted the need for a pharmacy education program to bring into focus the development of competence in clinical skills, entrepreneurship, leadership, and health innovation (DiPiro, 2011; Keshishian \& Brenton, 2011; Shaw et al., 2015). To achieve this, the pharmacy curriculum should be tailored towards developing critical thinking skills, problem-solving skills including entrepreneurship, and the expertise required to contribute professionally.

\section{Discussion}

As with many African countries, Zambia's pharmaceutical workforce of approximately 0.6 pharmacists per 10,000 people, is far lower than the WHO average of 5 pharmacists per 10,000 population (FIP Pharmacy education, 2020; Global Workforce Statistics, 2018.), this is a natural consequence of the lack of pharmaceutical education, as the FIP Nanjing statement (2017) states: 'there is no pharmaceutical workforce without pharmaceutical education'. Quality pharmaceutical training is therefore required to achieve universal health coverage (SDG, 2021).

The pharmaceutical education in Zambia is averagely sufficient in comparison with other countries of the African continent, which varied due to populations and historical background factors. In the authors view, Zambia does an averagely well with eight schools of Pharmacy which is equivalent to 0.16 per $1,000,000$ country population, while countries like Nigeria have 21 schools (0.1 per 1,000,000 with their high population) and Namibia of the same southern Africa subregion has one school of pharmacy which is equivalent to 0.4 per $1,000,000$ due to their smaller population size.

In terms of quality assurance, the regulation of pharmacy education in Zambia is carried out by the Higher Education Authority and Health Professionals Council of Zambia. This is not what is obtainable in many countries within the African region and globally. World over, pharmacy education is regulated by the pharmacy or pharmacist's council or board for example, in Kenya, the Pharmacy and 
Poison Board regulates pharmaceutical education and the Pharmacists Council of Nigeria regulates Nigerian pharmaceutical education. In the authors view, it would therefore be more fitting to govern pharmaceutical education by a separate and autonomous body, which is solely responsible for the regulation of pharmaceutical education.

The role of pharmacists has evolved to become more patients centred and clinically oriented as opposed to the previous practice of product-oriented approach. The authors deduced from this study that Zambia is lagging in this regard as in the majority of schools only offers traditional B.Pharm. degrees with with only one pharmacy school that offering a Pharm.D. programme.

As eight-star healthcare generals, pharmacists need the required expertise in the evolving global environment, however, like nearly all countries in Africa, Zambia appears to lacks the necessary educational equipment, technological knowledge, and facilitators for implementing digital training or even digital pharmacy practice as regards the FIP Nanjing statement (2017) for pharmaceutical education. Furthermore, this review has shown that, the postgraduate training of pharmacists in Zambia is grossly inadequate compared with what is obtainable in some African countries. For example, beyond obtaining a Master's degree in pharmacy (M.Pharm.) and other pharmaceutical sciences (such as masters in pharmaceutical analysis, clinical pharmacy, pharmaceutics, and the rest), countries in the West African region have a postgraduate college of pharmacists, where pharmacists are trained to become a consultant in their specialty, something similar to the residency programme found in the UK and USA. This enhances the competencies of pharmacy professionals and enables them to compete with their peers on the global stage.

\section{Study limitations}

The findings of this study are localised to Zambia, and therefore cannot be generalised to Pharmacy education in other countries. Also, the review did not cover more details on the curriculum of pharmacy education in Zambia, as such, further work needs to be done to comprehensively review the curriculum and make a valid recommendation that will improve the pharmacy education in Zambia to meet the international best practices.

\section{Recommendations}

To achieve the desired pharmaceutical workforce there is a need for more schools of pharmacy that will train competent pharmacists, to meet the United Nations' 'Health for All' agenda by the year 2030. The traditional 'compounding and dispensing only' role of pharmacists is becoming obsolete, as such the B.Pharm degree curriculum should be phased out and the adoption of the doctor of pharmacy (Pharm.D) is becoming necessary worldwide. Thus, Zambian pharmaceutical education needs to make this transition as quickly as possible.

There is an urgent need for postgraduate training for pharmacists in Zambia, covering both the Master of Science (M.Sc.), Doctor of Philosophy (Ph.D.), and postgraduate college for pharmacists (consultancy/ residency training). The Higher Education Authority and pharmaceutical interest group in Zambia should put allhands-on-deck to ensure that pharmacy education in Zambia is been regulated by the sole pharmacy board or council. Also, there is a need for regional and international cooperation to exchange ideas and review the curricula in schools of pharmacy in Zambia.

Moreover, with artificial intelligence (Al), machine learning $(\mathrm{ML})$, and the Internet of Things (IoT) the future belongs to those that embrace high-level technology. It's understandable and often agreeable that the curriculum is designed to reflect the local needs but we need to remember that the world is fast becoming a global village and healthcare practices are changing exponentially. As such some aspect of training pharmacists in Zambia needs to improve and lean towards digitisation agenda.

\section{Conclusion}

Pharmacy education has undergone a series of modifications over the past few decades in an effort to fulfil the changing demands of society. For a pharmacy education system to thrive, it must be continually evolving and driven by the needs of society or nation at hand at all times. This involves updating the pharmacist in training with up-to-date skills required of the modern-day pharmacist and research that enables continual improvement of the education system.

\section{References}

Anderson, C. \& Futter B. (2009). PharmD or needs-based education: which comes first? American Journal of Pharmaceutical Education. 73(5), Article 92. https://doi.org/10.5688/aj730592 
Anderson, C., Bates, I., Beck, D., Brock, T.P., Futter, B., Mercer, H., Rouse, M., Whitmarsh, S., Wuliji, T., \& Yonemura, A. (2009). WHO UNESCO FIP Education Taskforce. Human Resources for Health. 7(45). https://doi.org/ 10.1186/1478-4491-7-45

DiPiro, J.T. (2011). Preparing our students for the many opportunities in pharmacy. American Journal of Pharmacy Education, 75(9), Article 170. https://doi.org/10.5688/ajpe759170

FIP (International Pharmaceutical Federation). (2014). Quality assurance of pharmacy education: the global FIP framework (2nd Ed.). The Hague, Netherlands: international pharmaceutical federation (online). Available at: http://41.77.4.164.6510/www.fip.org/files/fip/ FIPEd_Global_Education_Report_2013.pdf

FIP (International Pharmaceutical Federation). (2017) FIP Nanjing Statements: Statements on Pharmacy and Pharmaceutical Sciences Education. The Hague: International Pharmaceutical Federation

FIP (International Pharmaceutical Federation). (2020) FIP pharmacy education in sub-Saharan Africa. The Hague: International Pharmaceutical Federation

Kalungia A.C., Muungo, L.T., Marshall, S., Apampa, B., May, C., \& Munkombwe, D. (2019). Training of pharmacists in Zambia: Developments, curriculum structure, and future perspectives. Pharmacy Education, 19(1), 69-78

Global Health Workforce Statistics (2018). The 2018 update, Global Health Workforce Statistics, (online). Available from: https:// www.who.int/data/gho/data/themes/topics/health-workforce

HPCZ (Health Professional Council of Zambia). (2016). Health Professions Council of Zambia Annual Report 2015 Lusaka, Zambia (online). Available from: http://www.hpcz.org.zm/download/?file=14944224511Report2015actual.pdf

Higher Education Authority. (2017). Providing Quality Assurance to higher learning institutions (online). Available from: http://www.hea.org.zm/ index.php

Kalungia C.A. \& Kamanga T. (2016). Patients' satisfaction with outpatient pharmacy services at the University Teaching Hospital and Ndola Central Hospital in Zambia. Journal of Preventive and Rehabilitative Medicine, 1(1), 16-21. https://doi/org/10.21617/jprm. 2016.0101.3

Keshishian, F. \& Brenton, B.P. (2011). Pharmacy students' perceptions of their curriculum and profession: implications for pharmacy education. Pharmacy Education, 11(1), 194-200

Lungwani T. M. Brief biography of pharmacy training in Zambia. (2015). Available at: https://www.slideshare.net/makoye1954/localpharmacists-training-development-history

Pearson G.J. (2007). Evolution in the practice of pharmacy--not a revolution!. CMAJ : Canadian Medical Association journal = journal de I'Association medicale canadienne, 176(9), 1295-1296. https://doi.org/ 10.1503/cmaj.070041

SDG (Sustainable Development Goals) (n.d.) Sustainable Development Goals (SDG) | SDG 3 targets (online). Available from: https:// www.who.int/health-topics/sustainable-development-goals\#tab=tab_2
Sosabowski M.H. \& Gard P.R. (2008). Pharmacy education in the United Kingdom. American Journal of Pharmaceutical Education. 72(6), 130. https://doi.org/10.5688/aj7206130

The World Bank. (2019). Population, total-Zambia. Available from: https://data.worldban.org/indicator/SP.POP.TOTL?locations=ZM

UNZA (University of Zambia). (2002). Curriculum for the Bachelor of Pharmacy (BPharm) Degree Programs, version 2002. Department of pharmacy. The University of Zambia. Lusaka, Zambia

UNZA (University of Zambia). (2013). Revised Curriculum for the Bachelor of Pharmacy (B. Pharm) Degree Program. Version 2013. Department of Pharmacy, University of Zambia. Lusaka. Zambia

UNZA. (2017). Revised Curriculum for the Bachelor of Pharmacy (BPharm) Degree, version 2017. Lusaka: The University of Zambia, Department of Pharmacy. Lusaka, Zambia

Whitmarsh S. (2008). The realities of professional education: The African Context. International pharmacy journal. 23(2), 34-38. Available from: https://fip.org/files/fip/pharmacyEducation/taskforce_IPJ_08.pdf 